\title{
The Impact of Technology Adoption on Agricultural Productivity and Production Risk in Ethiopia: Evidence from Rural Amhara Household Survey
}

\author{
Mulat Goshu Gebeyehu \\ Department of Economics, Wolaita Sodo University, Wolaita Sodo, Ethiopia \\ Email: mulatgoshu@gmail.com
}

Received 5 February 2016; accepted 19 February 2016; published 23 February 2016

Copyright (C) 2016 by author and OALib.

This work is licensed under the Creative Commons Attribution International License (CC BY). http://creativecommons.org/licenses/by/4.0/

(c) (i) Open Access

\section{Abstract}

The paper investigates the effects of modern farm technology adoption such as improved seed, fertilizer, pesticide and herbicide on both crop yield and downside risk exposure in Ethiopia. This study employed a two-stage approach to estimate a production function, and computed the mean and the production risk factors (both variance and skewness) from a production function using Antle's moment-based approach. The empirical results indicated that adoption of improved seed, family labor, agriculture capital and manure had a positive and significant effect on crop yield. On another hand, parcel size and chemical inputs (pesticide and herbicide) have negative and significant effect on crop yield. All these factors of production affect the crop yield variation and downside risk exposures (skewness of output) in differently ways: for instance, improved seed and chemical inputs positively and significantly affect the downside risk exposure (risk increasing), and fertilizer and parcel size significantly affect downside risk exposure but negatively (risk decreasing).

\section{Keywords}

Ethiopia, Agriculture Productivity, Production Risk and Technology Adoption

Subject Areas: Development Economics

\section{Introduction}

Majority of the poor in developing countries particularly Sub-Shara Africa countries heavily depend on agriculture for survival, as a result, agriculture is considered as a key fundamental for stimulating economic growth, 
overcoming poverty, and enhancing food security. Productivity increases in agriculture can reduce poverty by increasing farmers' income, reducing food prices and thereby enhancing increments in consumption as discussed by Diagne et al. [1]. In fact, agriculture growth is very fast in reducing poverty and food insecurity as compared to other sectors. Ligon and Sadoulet [2] estimated that 1\% GDP growth in agriculture in developing countries increased the expenditures of the poor at least 2.5 times more than the growth emanating from other sectors. Agriculture does not only an income source of every single nation, where most manufacturing industries as well as businesses are dependent on it. Without giving a serious attention on it, any country can be politically and economically unstable and paralyzed in any ways.

Agriculture is the major sector for Ethiopian economy. According to the latest statistics from the CSA, in 2014, agriculture currently contributes for $43 \%$ of nations' GDP, a leading source of jobs for over $75 \%$ of the population, and $90 \%$ of the foreign exchange earnings of the country. This shows how much the economy extremely depends on agriculture. By understanding these, Ethiopia began transforming its agriculture in the mid-1990s after the EPRDF-led government formulated a development strategy centered on agriculture. The strategy which is known as the Agricultural Development Led Industrialization (ADLI) sets out agriculture as a primary stimulus to generate increased output, employment and income for the people, and as the springboard for the development of other sectors of the economy. A green revolution like intensification of smallholder agriculture was seen as central by the government in implementing the strategy. Moreover, the recent Growth and Transformation Plan (GTP) aimed to reach certain goals in the growth of agricultural sectors between 2011 and 2015. Accordingly, bolstering smallholder farmers' productivity, enhancing marketing systems, upgrading participation of private sector, increasing volume of irrigated land and curtailing amount of households with inadequate food are some goals of GTP. Thus, all these can be achieved through improving public sector delivery programmes, especially intensifying agricultural extension delivery services for the dissemination of innovations and improved technologies of various kinds, expansion of rural finance and provision of incentives to the model farmers [3].

Unfortunately, agricultural production has always been risky, and production risk can be among the highly uncertain and potentially devastating which is a cause for uncertainty in consumption, profit and input choice decisions of farmers [4]. The climate change is the main source of production risks. The accompanied impacts of high temperatures, changed patterns of rainfall and possibly increased frequency of extreme events such as drought and floods, will probably combine to depress yields and increase production risks in many world regions, widening the gap between rich and poor countries [5]. A consensus has emerged that developing countries are under pressure from climate change and are more vulnerable to climate change than developed countries, because of the predominance of agriculture in their economies, the scarcity of capital for adaptation measures, their warmer baseline climates and their heightened exposure to extreme events [6].

In addition to weather conditions, pests, diseases, technology and its interaction with farm and management characteristics, genetics, equipment and quality of factor inputs are common sources of production risks. To reduce production risks, at micro level or macro level countries have been following different risk management strategies such as enterprise diversification, crop insurance, contract production, and evaluating new technologies. Due to the underdevelopment of credit and insurance schemes in many developing countries including Ethiopia, farmers usually protect themselves against shocks by adjusting their production and consumption decisions accordingly. This particularly applies through modern agricultural technology. Different literatures disclosed that increased farm technology development and adoption can raise agricultural output and reduce downside yield variability (see Kennedy \& Bouis [7], von Braun [8], Cochrane [9]). Similarly, different literatures (for example, Nin-Pratt \& Yu [10], Fuglie \& Rada [11]) discussed a positive and significant role of adoption of agricultural innovations (improved crops varieties) and other associated technologies such as fertilizer, herbicides and pesticides on progress of crop productions in sub-Sahara Africa.

Adoption improved farm inputs affects poverty and economic growth in different ways. Adoption of improved inputs like improved seeds, herbicide, pesticides and fertilizers increased the productivity as well as the income of adopters. On other hand the increment of production leads to lowering the price, increasing food access, employment creation and growth linkage effect. However, the use of agricultural technology in Ethiopia is trivial as compared to other developing countries. For instance the use of fertilizer in Ethiopia was $23.67 \mathrm{~kg}$ per hectare while the corresponding figures for Kenya, Malawi, Brazil and India were $44.31 \mathrm{~kg} / \mathrm{hec}, 39.89$ $\mathrm{kg} / \mathrm{hec}, 181.73 \mathrm{~kg} / \mathrm{hec}$ and $163.67 \mathrm{~kg} / \mathrm{hec}$ in 2012, respectively [12]. The reason behind low and stagnant agricultural productivity, non-adopting and low adoption rate of improved agricultural technologies must be identified to reduce poverty and improve the welfare of the society and growth of the economy. Consequently, this paper 
sought to measure the effects of applying modern farm inputs on yield productivity and down side risk exposures of the smallholder's farmers and to establish the factors that explain its variation across households. Substantial literatures have been examined the impact of modern farm inputs such as fertilize, improved seed, pesticide, herbicide on the productivity efficiency and the primary causes for low use of these inputs in Ethiopia (see, Birhanu et al. [13], Asfaw et al. [14] and Feleke et al. [15]). But none of these studies made the emphasis on impact of aforementioned technology adoption on production variation and downside risk exposure of farmers.

This study is somewhat unique in the sense that it accounts the effect of modern farm technology adoption on variance of output and down side production risks in developing countries. Using micro level case study approach, it assesses the sources of risks, risk coping strategies and risk attitude of the farmers to adopt new technology. Moreover, it measures the effects of technology adoption such as chemical fertilizer, improved seed, pesticide and herbicide on mean of output, variance of output and down side risk exposure of farmers in Ethiopia. Every author decides what variable to include and what not primarily depending up on the dataset they are working with. In this study, we are lucky enough from using a relatively rich panel dataset compared to previous studies that have been carried out within Ethiopia. This allowed us to include additional variables related to risk behavior of the households. Assessing technological impacts provides justification for termination, adjustment or further dissemination. This is essential to avoid technological failure and unpleasant benefits on adopters. The results are expected to important to strengthen the evidence-base for design and implementation of such a strategy so as to allow farmers make informed and critical decisions about their crops and maximized their benefits by adopting the technology.

The paper is organized, first part of the paper deals with general induction about the study focal points. While, in the second section, reviews of the theoretical and conceptual farm work are briefly presented. Data sources, methodology, result and discussion are organized in section three and four subsequently. Finally, section five summarizes the main findings, and present conclusion and policy recommendation.

\section{Conceptual Framework}

The primary objective of the study is to analyze the impact of modern technology adoption specifically fertilizer, improved seed and chemical inputs (herbicide and pesticide) on yield and production risks. We expected that adoption of fertilizer, improved seed and herbicide and pesticide increase yield and reduce production risks. For example adoption of improved seed increase yield and reduce risk through mitigating climate change impacts on production (such as drought-induced crop yield losses). For the analysis, the specification of production and production risk follow, Antle's [16] and Antle's [17] flexible moment based approach. The flexible moment based approach used the first moment (mean), second moment (variance) and the third moment (skewness) of production function to measure the impact of various inputs on yield and yield risk. The flexible moment based approach considered skewness of output as measurement of production risks. This specification allows the econometrician to differentiate the impact of inputs on output and risk, and has sufficient flexibility to accommodate both positive and negative marginal risks with respect to input [18] [19]. Here we used total output per hectare for selected crops as dependent variable and regressed this on vector inputs including labor, capital, land and other production shifters. In addition, we included the adoption improved seed, inorganic fertilizer and chemical inputs as explanatory variables.

To develop the conceptual framework, let as consider the neo classical producer-consumer model. Farm households especially in peasant farming production and consumption decisions are inseparable. The farm household that both produces and consumes the agriculture good is probably the classical prototype for such a model. Individual farm households have to decide which commodities to produce in which quantities, by which method, in which seasonal time periods. It is the objective of the farm households to maximize their utility, which deviates from pure profit maximizing behavior in many cases. In such case the technology adoption decision of the farmers is based on the risk behavior of the farm households and cost and benefit of new technology as compared to standard technology.

Assume farm households are price taker (both in input and output market) and any climate risk or technology risk affects the crop production yield. In such case risk averse farm households choose the input vector " $X$ " which maximized their expected utility based on the given output and input prices and a priori knowledge of the structure of the risky production technology. Let "Ui0" is utility of farmers non-adopting of modern agricultural technology and "Ui1" is utility of farmers adopting modern agricultural technology. Farmers adopt the modern 
agricultural technology if and only if "Ui1" is greater than "Ui0".

Which implies that very low level of utility or incentive of the new technology which the farmer will not adopt the new technology, but at a sufficient high level of utility of the new technology, the farmer will mostly adopt new technology. Considered the following production function:

$$
Q=F\left(X^{F t}, X^{S t}, X^{P t}, X^{O t}\right)
$$

where $Q$ is output, $X^{F t}$ is fertilizer used at time " $t$ " $X^{\text {St }}$ is improved seed used at time " $t$ " $X^{p t}$ is chemical input (pesticide and herbicide) used at time " $t$ " $X^{\text {Ot }}$ is other inputs used by farmers at time " $t$ ". The production functions $F($.$) is assumed a continuous and twice differentiable Koundouri et al., 2006$ [20]. Under risk and uncertainty, assume the utility is a von Neumann-Morgenstern utility function representing the risk preferences of the farm households. The expected utility maximization problem for risk adverse farmers as function of profit is presented by

$$
\begin{aligned}
& \operatorname{Max} E[U(\pi)] \\
& =\max \int_{0}^{Q}\left[U\left(p f\left(X^{F t}, X^{S t}, X^{P t}, X^{O t}, \varepsilon^{t}\right)-w^{F} X^{F t}-w^{S} X^{S t}-w^{h} X^{h t}-w^{o} X^{o t}\right)\right] \mathrm{d} G(\varepsilon)
\end{aligned}
$$

where $U($.$) is the Von Neumann-Morgenstern utility function, P$ is output price, $w$ is input price, $E$ is the expectation operator, " $\varepsilon$ " while captures all the unobserved household heterogeneity such as unreported farm management ability, land fertility, risk preferences and risk management ability which could affect input use and farm productivity. The first order condition (FOC) for fertilizer input specified as follow

$$
\begin{gathered}
E\left[w^{f} U^{\prime}\right]=E\left[p \frac{\partial f\left(X^{F t}, X^{S t}, X^{h t}, X^{O t}, \varepsilon^{t}\right)}{\partial X^{F t}} * U^{\prime}\right] \\
w^{f} E\left(U^{\prime}\right]=P E\left[\frac{\partial f\left(X^{F t}, X^{S t}, X^{h t}, X^{O t}, \varepsilon^{t}\right)}{\partial X^{F t}}\right] * E U^{\prime} \\
+\operatorname{cov}\left[U^{\prime}, \partial f\left(X^{F t}, X^{S t}, X^{h t}, X^{O t}, \varepsilon^{t}\right) / \partial X^{F t}\right] \\
\frac{W^{F}}{P}=E\left[\frac{\partial f\left(X^{F t}, X^{S t}, X^{h t}, X^{O t}, \varepsilon^{t}\right)}{\partial X^{F t}}\right]+\frac{\operatorname{cov}\left[U^{\prime}, \partial f\left(X^{F t}, X^{S t}, X^{h t}, X^{O t}, \varepsilon^{t}\right) / \partial X^{F t}\right]}{E\left(U^{\prime}\right)}
\end{gathered}
$$

where $U^{\prime}=\frac{\partial U(\pi)}{\partial \pi}$ for risk neutral framers the ratio of input price to output price is equal to the expected marginal product of the fertilizer inputs which means the second term of the Equation (5) will disappeared. However, in case of risk averse the second term of Equation (5) is different from zero and it measures the deviation risk neutrality situations. The term would be proportional and opposite in sign to the marginal risk premium with respect to the input under consideration [20].

The case of risk neutrality the optimal input decision can be find using standard approach of equating ratio of input price to output price to expected marginal product $\left(\frac{W^{F}}{P}=\frac{\partial f}{\partial X^{F}}\right)$. However, presences risk averse and market imperfection the optimal input decisions depend on the shape of utility function $U($.$) , production function$ $F($.$) and risk function G($.$) [21]. Solving Equation (5) mathematically is very difficult. In addition to this, to es-$ timate risk function parametric and risk preference the distribution " $\varepsilon$ " is required. For the same reason [16] [17] proposed the flexible moment based approach. The approach provides a general econometric methodology for estimating higher moments of output as functions of inputs. Thus, given input and output data for a production period, there exist means of modeling and estimating the effects of alternative production practices and input combinations on production risk [16] [17]. According to the Antle model maximizing the expected utility of profit with respect to any input is equivalent to maximizing a function of moments of the distribution of " $\varepsilon$ ", those moments having themselves " $X$ " as an argument. This is given by: 


$$
\operatorname{Max} E[U(\pi)]=F\left[\mu_{1}\left(X^{f t}, X^{s t}, X^{h t}, X^{o t}\right), \mu_{2}\left(X^{f t}, X^{s t}, X^{h t}, X^{o t}\right), \cdots, \mu_{m}\left(X^{f t}, X^{s t}, X^{h t}, X^{o t}\right)\right]
$$

where $\mu_{i}=(i=1,2, \cdots, m)$ is the $m^{\text {th }}$ moment of farm profit, and $F($.$) is a cumulative distribution function and$ completely unspecified. Using the FOC of this problem, the marginal impact of modern farm inputs for example fertilizer input on the first moment is given by:

$$
\begin{aligned}
\frac{\partial \mu_{1}\left(X^{f t}, X^{s t}, X^{h t}, X^{o t}\right)}{\partial X^{f t}} & =\alpha_{1} F+\alpha_{2} F \frac{\partial \mu_{2}\left(X^{f t}, X^{s t}, X^{h t}, X^{o t}\right)}{\partial X^{f t}} \\
& +\alpha_{3} F \frac{\partial \mu_{3}\left(X^{f t}, X^{s t}, X^{h t}, X^{o t}\right)}{\partial X^{f t}}+\cdots+\alpha_{m} F \frac{\partial \mu_{m}\left(X^{f t}, X^{s t}, X^{h t}, X^{o t}\right)}{\partial X^{f t}}+v^{f t}
\end{aligned}
$$

Similarly we can derive for improved seed and chemical inputs

\section{Specification Empirical Model for Production and Production Risk Function}

To estimate the outlined model in conceptual framework, we need to assume parametric form for the production function. The household production function is presented in the forms of Cobb-Douglas production function:

$$
Y_{i t}=\beta_{0}+\pi x_{i t}^{\beta_{i}}+U_{I T}
$$

where $y_{i t}$ is the total yield value ${ }^{1}$ of five selected crops namely teff, wheat, barley, sorghum and maize. The crop were selected based the criteria commonly and dominantly produced by sample households. The vector of inputs “ $x$ ” includes, land size, capital, labor, fertilizers, a manure, chemical inputs, improved seed, local seed and irrigation; and demographic factors. To estimate the effects agricultural inputs on crop production risk, first $i_{\text {th }}$ central moment of output about its mean will be computed as:

$$
\varepsilon_{i}=\varepsilon\left(y_{i t}\left(x_{i t}, \text { Dit, } \beta_{i}, \mu_{t}\right)-\mu\right)
$$

where, " $\mu$ " is the mean output or the first moment of yield per hectare. To generate the second moment of yield, first we estimated residuals from the mean regression which is estimated of the first moment of yield distribution then after making it squared (variance) it become regressed against the same variables to measure the impact of input on yield variances. Therefore variances of yield as function of all the same factor include in the production model specified as follow

$$
\varepsilon_{i t}^{2}=\varepsilon\left(y_{i t}\left(x_{i t}, \text { Dit, } \beta_{i}, \mu_{t}\right)-\mu\right)+v i t
$$

By applying similar procedure we will estimate the third central moment (skewness) of yield production distribution (in this case the estimated errors were raised to power three).

$$
\varepsilon_{i t}^{3}=\varepsilon\left(y_{i t}\left(x_{i t}, \text { Dit }, \beta_{i}, \mu_{t}\right)-\mu\right)+u i t
$$

\section{Study Area, Data and Sampling Procedure}

To achieve the stated objective, the study was used both the two year cross sectional data obtained from a household survey project entitled "The Ethiopian Project on Interlinking Insurance with Credit in Agriculture (EPIICA)”. The survey jointly conducted by university of California, San-Diego, university of Athens, university of Greece and FAO, EEA, Dashen Bank and Nyala Insurance company during 2011 to 2013 in Amhara region. The primary intention of the survey is to promote the use of fertilizers by smallholder farmers and hence boosting productivity [22]. In early 2011, EPIICA conducted its baseline survey [23].

Using well-organized questionnaire, detail information was collected on several issues including households' demographic characteristics, asset endowments, access to credit, membership in different rural institutions, income sources, crop and livestock production, use of technology, information's related to risk and attitude to weather index insurance(WII). Regarding the sampling technique, surveys was based on Nyala Insurance share

\footnotetext{
${ }^{1}$ Aggregate output corresponds to the total value of production of teff, wheat, maize, sorghum and barley (measured in birr). The crops were selected based on the criteria which commonly and dominantly produce by households in the study area. According to the CSA (2010/11) post-harvest survey shows cereal crops covered up to 70 percent of crop production. Among cereals teff, wheat, maize, sorghum and barely are dominantly produce in Ethiopia particular in selected zones.
} 
Company's informed opinion based on best potential to purchase WII, zone and then kebelles from selected zones purposively. The survey was conducted in four zone, west Gojjam, north Shewa, south Wello and north Wello of the Amhara region. The survey covers 120 kebelles and households within the selected kebelles were randomly sampled to participate in the study; in each village 18 cooperative member households and 2 households that are not a member of the primary cooperative were selected [23].

\section{Study Case}

This part basically deals with an in depth investigation of potential determining factors of the production, and downside risk exposures of smallholder farmers in the selected zones in Amhara region. In doing so, the first task starts from discussing sources of crop production risk, technology adoption behavior and risk coping mechanisms. Econometric estimation results of the determinants of mean production and production risk are discussed following the supplement information generated from the descriptive statistics.

\subsection{Sources of Crop Production Risk}

The crop production is faced with risks associated with the negative outcome arising from unpredictable weather events and biological variables. Climate change (like, drought, much rainfall, flooding, etc.) are not under the control of producers, along with pest and plant disease adversely affects the production outcome. The survey also asked sample households to rank the three major shocks that had negative income effects and which happened during the production period. The smallholder farmers in the study area faced multiple, recurring and substantially risks in their crop production process and livelihood, including drought, heavy rainfall, flooding, untimely rains, hailstorm, plant disease, pest damage, loss, and death of animal livestock, and illness. Table 1 summarizes the risks to crop production experienced by smallholder farmers.

The table revealed that drought is the main sources of production risk in the study area. The most immediate consequence of drought is a fall in crop production, due to inadequate and poorly distributed rainfall. Farmers had faced with harvests that were too small to both feed their families and fulfill their other necessities. The prevalence of drought has affected $23.55 \%$ of all households surveyed during the 2011 survey. The sampled administrative zones where relatively larger drought affected households found is North Wello with $44.9 \%$ whereas, in South Wello about $25.7 \%$ of the households had affected by drought. North Shewa possesses about $22.05 \%$ of all households surveyed that are influenced by drought. On the other hand the lowest number of households affected by drought is registered in West Gojjam which accounts about 7.35\% during the 2011 survey. Moreover, we can argue that households who live in North and South Wello zones are mostly affected by drought than those live in North Shewa and West Gojjam. It may be due to the fact that the former two zones are characterized by drought occurring frequently, average rain fall is low, and rain is highly erratic with frequent shock and crop failure.

Table 1. Summary of the risks to crop production experienced by smallholder farmers (in percentage).

\begin{tabular}{|c|c|c|c|c|c|c|c|c|c|c|}
\hline \multirow{2}{*}{ Type of Production risk } & \multicolumn{5}{|c|}{2011} & \multicolumn{5}{|c|}{2013} \\
\hline & $\begin{array}{l}\text { North } \\
\text { Shewa }\end{array}$ & $\begin{array}{l}\text { West } \\
\text { Gojjam }\end{array}$ & $\begin{array}{l}\text { South } \\
\text { Wello }\end{array}$ & $\begin{array}{l}\text { North } \\
\text { Wello }\end{array}$ & total & $\begin{array}{l}\text { North } \\
\text { Shewa }\end{array}$ & $\begin{array}{l}\text { West } \\
\text { Gojjam }\end{array}$ & $\begin{array}{l}\text { South } \\
\text { Wello }\end{array}$ & $\begin{array}{l}\text { North } \\
\text { Wello }\end{array}$ & total \\
\hline drought & 22.06 & 7.35 & 25.74 & 44.85 & 23.55 & 23.20 & 35.04 & 26.86 & 14.90 & 70.91 \\
\hline $\begin{array}{l}\text { heavy rainfall, flooding, } \\
\text { untimely rains, hailstorm }\end{array}$ & 21.38 & 25.92 & 38.44 & 14.25 & 40.09 & 55.65 & 29.13 & 10.87 & 4.35 & 19.91 \\
\hline $\begin{array}{l}\text { major harvest losses due to wild } \\
\text { animals, birds, livestock, Insects, } \\
\text { pests }\end{array}$ & 48.48 & 32.53 & 13.79 & 29.63 & 8.57 & 41.71 & 29.15 & 27.14 & 2.01 & 17.23 \\
\hline loss, death, of animal & 43.68 & 35.63 & 12.64 & 8.05 & 7.53 & 20.41 & 52.04 & 17.35 & 10.20 & 8.48 \\
\hline illness & 33.66 & 33.66 & 33.66 & 33.66 & 8.74 & 35.23 & 35.23 & 22.73 & 6.82 & 7.62 \\
\hline Others (forest, wage, hell, flood) & 22.97 & 22.97 & 22.97 & 22.97 & 6.41 & 37.08 & 34.65 & 24.62 & 3.65 & 28.48 \\
\hline
\end{tabular}

Sources: Authors’ calculations from EPIICA 2011 \& 2013 survey. 
The heavy rainfall, flooding, untimely rains, hailstorm were other important sources of crop production risks, where $40.09 \%$ and $19.19 \%$ of the sample households had lost their crop production in 2011 and 2013, receptively. The plant disease, pest damage, loss, and death of animal livestock, and illness were also major sources of crop failure for the households which cause significant crop and income loss and aggravated food insecurity. These factors not only endanger the farmer's livelihood and income but also undermine the viability of agriculture sectors emergence as a solution to the problem of poverty and food insecurity of the nation.

\subsection{Risk Coping Strategies of the Households}

Agriculture (particularly crop production) is the main sources of livelihood strategies (food and income) for farm households. Accordingly, when households experienced crop production risk directly it will affect food availability and hence they will be faced food shortage. Consequently, they respond that they adjusted their consumption like eating non normal or less expensive goods, reduce the frequency or amount of meal, receive assistance, borrowing, engaging new ways of generating income, migration, using saving cash and sell fixed assets.

Table 2 presents the percentage of households of coping strategies to deal with impacts on their agricultural production and food security. Accordingly, 10.5 percent (in 2011) and 19.2 percent (in 2013) of the households used their saving cash or sell fixed asset to cope up with food shortage. Engaging new ways of income generating activities are very important, with 30.9 percent (in 2011) and 32.5 percent (in 2013) of households indicating that their family members were engaged in new income generating activities when they faced crop failure and food shortage.

Social network is also an important coping strategy for the households with food shortage, which accounts 4.9 percent (in 2011) and 3.7 percent (in 2013) of the households reported that they get assistance from the family and others and 2 percent (in 2011) and 4.9 percent (in 2013) of the households borrowed money from family, neighbors, and any local institutions. Households also responded that food shortage problem reduces the frequency or amount of meals. Around 13.1 percent and 31.1 percent of the households indicated that they reduced the frequency and amount of their family meal in 2011 and in 2013, respectively. Another important means of coping food shortage problem that was reported by households is consuming non normal or less expensive foods which were reported by 14.8 percent and 13.1 percent of the households in 2011 and 2013, respectively.

\subsection{Risk Attitude of the Farmers and New Technology Adoption}

Risk attitude of farmers is largely documented in the literatures as a critical factors that influences the farmer's adoption decisions for example [21] [24] suggested that risk-averse or more riskiness farmers are less likely to adopt new technologies, despite the risk reducing and income increased of the new technologies. However, Binswanger [25] argues that risk-averse farmers look for new technologies for risk reducing strategies and they may more potentially adopt new technologies.

Hence, 52.5 percent of the farm households indicted that they were willing to take risks related to adoption of new technologies, 42.5 percent reported that they cautions in taking such risk, while 4.8 percent of the house-

Table 2. Household's coping strategies to deal with risk in the study Area.

\begin{tabular}{|c|c|c|}
\hline Coping strategies & $2011(\%)$ & $2013(\%)$ \\
\hline cash savings/sell or exchange assets & 10.5 & 19.2 \\
\hline receive assistance from family or others & 4.9 & 3.7 \\
\hline engage in new ways of generating income & 30.9 & 32.5 \\
\hline eating non normal/less expensive food & 14.8 & 13.1 \\
\hline migration of some $\mathrm{HH}$ member to other places & 1.0 & 1.2 \\
\hline borrowing & 2.0 & 4.9 \\
\hline reducing frequency of /amount of meal & 13.1 & 31.1 \\
\hline
\end{tabular}

Sources: Authors’ calculations from EPIICA 2011 \& 2013 survey. 
holds never take such risk (risk averse) in 2011 survey (see Table 3). Moreover, the table reveals that 55.8 percent of households are willing to take risks that arise from the use of new technologies that improve their income (risk taker), 36.7 percent are cautious in taking new technology risks and 7.4 percent stated that they never take such risk (risk averse) during the 2013 survey. The result suggests that the majority of farm households are willing to take risk as result of new technologies adoption.

The 2013 survey asked sample households "where would you place yourself in relation with willingness to take risks of using new technologies? (taking scale of 0 to 10)" Where, the value 0 means "not willing at all to take risks and the value 10 means "very willing to take risks to improve their income. Accordingly, Only 1.13 percent of the farm households are not willing at all (selected zero) and relatively small proportion of the households chose from 1 to 4 which is $1.56 \%, 2.51 \%$, 3.98\%, and $7.19 \%$ of the household surveyed, respectively. Majority of the households placed themselves from 5 to10 which is $14.89 \%, 14.55 \%, 13.25 \%, 15.06 \%$, $5.54 \%$ and $20.35 \%$ of the total sampled, respectively. Thus, we can say that the majority of the farm households are willing to take risks due to use of new technologies in order to increase their production and income (Table 4).

\subsection{Econometric Estimation Results: Impact of Technology Adoption on Crop Yield and Crop Production Risks}

The leading objective of the study was to examine the impact of modern agricultural technologies adoption namely improved seed, inorganic fertilizer and chemical inputs on crop yield and crop production risk. To this end, first the log of value of agricultural yield per hectare for selected cereals was regressed using production inputs, different farm specific factors, and household demographic characteristics. The estimated error term was

Table 3. Percentage of households in each risk behavior.

\begin{tabular}{cccccc}
\hline \multirow{2}{*}{ Types of Risky behavior } & \multicolumn{2}{c}{2011} & \multicolumn{2}{c}{2013} \\
\cline { 2 - 5 } & frequency & percentage & frequency & Percentage \\
\hline Risk taker & 606 & 52.5 & 645 & 55.8 \\
Risk neutral & 493 & 42.7 & 424 & 36.7 & 7.4 \\
Risk avers & 56 & 4.8 & 86 & 1155 & 100 \\
\hline total & 1155 & 100 & & & \\
\hline
\end{tabular}

Sources: Authors’ calculations from EPIICA 2011 and 2013 survey.

Table 4. Households risk taking level and percentage of households.

\begin{tabular}{ccc}
\hline Scale (risk taking level) & Frequency & Percentage \\
\hline 0 & 13 & 1.13 \\
1 & 18 & 2.51 \\
2 & 29 & 3.98 \\
3 & 46 & 7.19 \\
4 & 83 & 14.89 \\
5 & 172 & 14.55 \\
6 & 168 & 13.25 \\
7 & 153 & 15.06 \\
8 & 174 & 5.54 \\
\hline
\end{tabular}

Sources: Authors’ calculations from EPIICA 2013 survey. 
then raised to the power of three and regressed on the same set of variables to generate the third order moment of output (skewness) which is the measurement of crop production risk. Both the output model and output risk functions are estimated using mundlak random effect model. Mundlak [26] relax the strictly exogenous assumption explanatory variable conditional disturbs term (Uit) and he assumed they may correlated. According to mundlak unobserved variable may correlated with means of time variant variables. The model had been included the within means of time variant variables as an additional explanatory variables to control unobserved heterogeneity.

The estimation results are show in Table 5 we expected that the use of inorganic fertilizer (like dap and urea) can help to increase organic matter in soils, on their own they contain insufficient inorganic nutrients to meet the needs of crops and thus could increase yield. The finding revealed quantity of inorganic fertilizer used had positive but, insignificant effects on mean value of yield. Many of the respondents adopt inorganic fertilizer and had no significant difference on intensity of fertilizer used among the smallholder farmers. Econometrics estimation need data variation among individual which may cause the insignificant effects of inorganic fertilizer on mean output.

Parameter estimate of quantity of improved seed use had positive and significant effect on value of mean yield. This is due to the reason, from the beginning improved seed produced to responsive to complementary inputs like fertilizer and they may drought resistances. In the opposite, local seed had negative and significant impact on yield. It is significant at $1 \%$ level. An increased quantity of local seed by one unit, yield would decrease by $9.7 \%$. This may be due to the reason that local seeds produced by farmers have lower quality and are less productive as compared with the improved seed. Furthermore local seeds may be less responsive to the use of complementary inputs like fertilizer and may not be pest resistance.

Chemical inputs were found to have negative and significant impact on yield. Use of chemical inputs (pesticide and herbicide) by farmers is expected to keep crop healthy and protect it from pest, disease and reduce weeding time and effort. However, chemical inputs have negative impact on environment and will reduce yield output. The use of chemical inputs like herbicide and pesticide require knowledge [27]. As it obvious most of the farmers are illiterate and they may not apply chemical inputs based on the recommended level per hectares. Even though chemical inputs are important to control weed, pest and plant disease, there are also disadvantages to the use of chemical inputs. Chemical inputs pose danger to the environment and non-target organisms can be severely impacted. For example a pest insect is controlled by beneficial insects, predators or parasite, yet the insecticide application kills both the pest and the controlling organism. Chemical inputs are reducing the fertility of land and the growth of plant.

The education status of the household head is categorized in four dummy variables, household head with no education, those with informal education, those with primary education and those with secondary and above education. The "no education" is considered as the base dummy variable without any precondition. The parameter estimate of secondary education and above had statistically significant and positive impact on yield at 5\% level. This demonstrate that education emerges as an important factor in enhancing agricultural productivity, since education increases the ability of farmers to use their resources efficiently and the allocate effect of education enhances farmers` ability to obtain, analyze and interpret information. The result also shows that there is no significant difference between household heads attended primary and informal education and those with no education on yield.

The family labor size had positive and significant effect on mean yield for sampled households at 5 percent of significance. The estimated coefficient for hired labor dummy is insignificant. The result reveals that households who have larger family size can increase yield than households with small family labor. While most of the households depend on only family labor 74.9 percent around 25.1 percent used hired labor in the 2013 survey. Labor requirement during the harvesting and planting period is high; households who have large family labor size can handle it effectively. Furthermore the positive and significant impact of family labor on mean output may be due to the reason that family labor is more efficient than hired labor mainly because family labor is more motivated than hired labor [28].

Another factor that affects the mean yield is land size. Its estimated coefficient was negative and significant at 5\% level, indicating that farmers with more land are unlikely to increase yield. An increase in land size by 1 hectare would decrease yield by $44.5 \%$. The negative effect of farm size on the value of crop production is consistent with the literature [28] [29] indicated that management labor, finance, new technology, like fertilizer, improved seed or other constraints limit the ability of larger farmers to be as productive as smaller farmers. 
Table 5. Determinants of the of agricultural mean yield value and agricultural output risks.

\begin{tabular}{|c|c|c|c|c|c|c|}
\hline \multirow{3}{*}{ Explanatory variables } & \multirow{2}{*}{\multicolumn{2}{|c|}{ Value of yield per hectare }} & \multicolumn{4}{|c|}{ Downside risk measurement } \\
\hline & & & \multicolumn{2}{|c|}{ Variance of output } & \multicolumn{2}{|c|}{ Skewness of output } \\
\hline & Coef. & Std. Err. & Coef. & Std. Err. & Coef. & Std. Err. \\
\hline Informal education dummy & 0.098 & 0.053 & -0.119 & 0.127 & 0.647 & 0.683 \\
\hline $\begin{array}{l}\text { Dummy for primary education by household } \\
\text { head }\end{array}$ & -0.090 & 0.056 & 0.092 & 0.134 & 0.833 & 0.719 \\
\hline $\begin{array}{l}\text { Dummy for secondary and above education } \\
\text { by household head }\end{array}$ & $0.201^{* *}$ & 0.073 & $-0.369 *$ & 0.176 & 0.215 & 0.943 \\
\hline Dummy for households in West Gojjam & $0.174^{*}$ & 0.079 & $0.424 *$ & 0.183 & -1.098 & 0.984 \\
\hline Dummy for households in south Wello & $-0.205^{* * *}$ & 0.059 & $0.707 * * *$ & 0.137 & 0.292 & 0.735 \\
\hline Dummy for households in North Wello & $0.177^{*}$ & 0.077 & -0.102 & 0.179 & -0.344 & 0.960 \\
\hline Log of family labor( age $>=15$ ) & $0.148^{*}$ & 0.063 & 0.23 & -0.23 & -0.001 & 0.003 \\
\hline Hired labor dummy ( 1 = hired, 0 = otherwise) & 0.050 & 0.053 & 0.039 & 0.126 & 1.055 & 0.678 \\
\hline Percentage of Irrigation land & -0.001 & 0.001 & 0.001 & 0.002 & -0.004 & 0.013 \\
\hline Tropical livestock unit & -0.022 & 0.017 & -0.033 & 0.042 & 0.163 & 0.225 \\
\hline Log of parcel in hectare & $-0.445^{* * *}$ & 0.042 & $0.570^{* * *}$ & 0.104 & $0.737^{* *}$ & 0.556 \\
\hline Log of agriculture capital & $0.276 * * *$ & 0.039 & $0.266^{* *}$ & 0.097 & 0.421 & 0.522 \\
\hline Log of manure used in $\mathrm{kg}$ & $0.024 *$ & 0.011 & -0.016 & 0.028 & -0.198 & 0.148 \\
\hline Log of local seed used in $\mathrm{kg}$ & $-0.097 * * *$ & 0.018 & -0.006 & 0.044 & -0.390 & 0.238 \\
\hline Log of inorganic fertilizer in $\mathrm{kg}$ & 0.008 & 0.018 & $-0.122 * *$ & 0.044 & $-0.077^{*}$ & 0.238 \\
\hline Log of improved seed used in $\mathrm{kg}$ & $0.116^{* * *}$ & 0.033 & 0.032 & 0.082 & $1.538^{*}$ & 0.438 \\
\hline Log of chemical inputs used in litter & $-0.065^{*}$ & 0.024 & -0.023 & 0.059 & $0.814^{*}$ & 0.319 \\
\hline \multicolumn{7}{|l|}{ Mean of time variant expletory variables } \\
\hline Mean LNFER & 0.043 & 0.023 & 0.061 & 0.056 & -0.160 & 0.300 \\
\hline Mean LNIMSEED & $-.160 * * *$ & 0.048 & 0.014 & 0.115 & -0.524 & 0.616 \\
\hline Mean LNPEH & -0.028 & 0.035 & -0.112 & 0.084 & -0.532 & 0.452 \\
\hline Mean LNMANURE & $0.040^{*}$ & 0.016 & 0.003 & 0.038 & 0.098 & 0.206 \\
\hline Mean LNLOSEED & $0.215^{* * *}$ & 0.034 & -0.100 & 0.081 & -0.431 & 0.434 \\
\hline Mean LNLANDSIZE & 0.087 & 0.057 & $-0.349 *$ & 0.139 & 0.744 & 0.744 \\
\hline Mean LNAGRCAPITAL & $-0.111^{*}$ & 0.050 & $-0.297^{*}$ & 0.122 & 0.470 & 0.652 \\
\hline Mean TLU & $0.080^{* * *}$ & 0.023 & -0.041 & 0.057 & -0.092 & 0.304 \\
\hline Mean LNFAML & $0.149^{*}$ & 0.059 & 0.041 & 0.136 & -0.721 & 0.730 \\
\hline Mean IRRLAND & 0.000 & 0.001 & -0.001 & 0.003 & -0.008 & 0.017 \\
\hline _cons & 7.433 & 0.191 & 1.249 & 0.443 & -3.876 & 2.378 \\
\hline Wald chi2(17) & 546.54 & & 115.73 & & 670.48 & \\
\hline Prob $>$ chi2 & 0.0000 & & 0.0000 & & 0.0000 & \\
\hline Number of obs. & 1125 & & 1125 & & 1125 & \\
\hline
\end{tabular}

where *,** and *** indicate significant variables at $5 \%, 10 \%$ and $1 \%$ levels of significance. The values in parenthesis are robust standard errors for each of the respective coefficients; Note: from the continuous variables "LN" indicates the natural logarithm of the variables. 
Agricultural capital is found to have a positive and significant on yield. It is significant at $1 \%$ level. When the agriculture capital increases by 1 unit, yield would increase by 27.6\%. In fact more agricultural tools (capital) can increase the efficiency of farmers through increasing the efficiency of other complementary inputs.

The coefficient of manure was found to be statistical significance at $5 \%$ level having positive effect on the mean yield. When the use of the quantity of manure increases by 1 unit, mean yield would increase by 2.4 percent. The result may be explained by the ability of manure to hold water and nutrients that would improve the structure of soil and thus increase the yield. In addition, the use of organic fertilizer helps the farmer to reduce the cost of inorganic fertilizer because manure can be prepared locally on the farm itself. Hence, the cost of these fertilizers is much lower than the cost of chemical fertilizers.

It is obviously geographic location of farms determines cropping patterns, rainfall amounts, and soil productivity. As noted earlier we used three locational dummy (such as North Wello, South Wello and West Gojjam) to represent the farmers location and we used North Shewa as base dummy without any pre conditions. The mean function estimated result revealed that both North Wello and West Gojjam were statistically significant at 5\%. Results indicate that compared to farms in the North Shewa (the benchmark), North Wello and West Gojjam dummy were statically significant and a positive impact on yield for the sampled households. Implies North Wello and West Gojjam farms were more likely to increase yield as compare to farms in North Shewa. The result consistent with descriptive analysis, many of the households live in North Shewa report was faced much rainfall, beredo, flooding than other zones. Other hand South Wello farms were more unlikely to increases yield. This result is not surprising because farmers in South Wello frequently affected by environmental risk(drought, late coming rain) and the land is less fertile as compare to west Gojjam and north Shewa.

In Table 5, the estimation result of downside risk exposure measurements revealed that some of the inputs are not equally important in explaining the crop production risk estimates as compared with the estimation of the mean yield. Thus, some variables are significantly affecting crop production risk while some remains statistical insignificant in explaining the variation in crop production risk. The result confirms that land size had a significant and positively impact on crop production variation and it had a negative and significant effect on skewness of output which was used as measurement of downside risk exposure (risk increasing factor). It possesses the prior expectation sign and gives an economic meaning. That is increase in the usage of land size will lower the ability to discover unfavorable conditions early, and therefore increase the output risk.

Unlike the previous studies, we found that inorganic fertilizer had a negative and significant effect on crop output on the second and third moment function of output (risk decreasing factor). An increase in the use of fertilizer is therefore expected to increase crops and prevent exhaustion of the soil. However, at some point increased concentration of fertilizer ceases to cause an increase in crops, instead possibly resulting in poisoning and reducing the crop [30]. This argument is directly related to the application rate of inorganic fertilizer, if the farmers apply more fertilizer on own farm it will increase the concentration of fertilizer which may cause poisoning and reducing yields. But, as indicated in the literature the application rate of inorganic fertilizer in Ethiopia is very low and it is below the recommended rate of $200 \mathrm{~kg}$ per ha (100 kg of Dap and $100 \mathrm{~kg}$ of Urea). Therefore, the use of inorganic fertilizer may not cause the crop failure rather it reduces crop failures due to lack of soil nutrient.

The use of improved seed had positive and significant impact on the third moment function output (Skewness of output). The positive sign of the estimated coefficient of improved seed shows that it is a risk increasing factor. The use of improved seed is expected to increase the crop production, when they are locally adaptable to drought, pest and disease resistance. But, in our country in most cases improved seeds are developed and distributed without the consideration of agro ecological difference and thus could increase crop production risk. The study by [31] suggest that farmers in Ethiopia faces multiple challenges related to supply and quality of improved seed including limited capacity and lack clarity on the role of the different actors, the focus of the system on very few crops and varieties, mismatch between supply and demand resulting in shortage and excess inventory, and degradation of seed quality because of inappropriate production practices, storage and transport facilities. All these factors make improved seed a less productive and risk increasing factor.

The estimated coefficient for Chemical inputs (pesticide and herbicide) was significant and positive on down side risk exposure. This implies that pesticide and herbicide are risk increasing factors of production. The result is consistent with the study [32] says that herbicide and pesticide technology solves the complex approaches to weed control and pest control and thus could reduce crop yield risks. Synthetic pesticides and herbicides have all been critical to protecting crop yields. 


\section{Conclusion and Policy Implications}

In Ethiopia, agriculture is the main sources of income and livelihood for rural households and the bases for the whole economy at large. However, agriculture has remained under developed. This is due to a mix of different factors including: agriculture production heavily dependent on rainfall, recurrent drought, low productivity, weak infrastructure, small land holding, fragment and imperfect financial market and low adoption of modern agricultural technologies. Empirical evidence suggested that production risks were often attributed to low adoption of agricultural technology and low productivity.

An inherent characteristic of crop production in Ethiopia is the high production risk due to adverse weather conditions, pest and disease. Because of absence of poorly developed credit and insurance markets, it is difficult for farm households to overcome any of these risks. Consequently, farm households base their production decisions, in part, on the perceived risk of failure. Farmers are not sure of changes due to a range of factors including weather and new technology which may make things difficult for them to predict the future with certainty. Thus, a better understanding on impact of modern technology adoption on production and production risk is essential for appropriate farm level policy.

The study examined the effect of modern agricultural technology adoption on crop production and production risk in Ethiopia using the two round EPIICA household survey in 2011 and in 2013.The study tried to identify the main sources of crop production risks for the entire sampled zones and almost all of sample households are affected, at least by one source of, crop production risk. Drought is the main source of the crop production risk where, about 23.55 percent (in 2011) and 70.91 percent (in 2013) of the households had lost their harvest partially or fully. Consequently, their income and consumption had been adversely affected. The households who live in North and South Wello were seriously affected by drought due to low average annual rain fall and erratic nature of rain. The heavy rainfall, flooding, untimely rains, hailstorm were other important sources of crop production risks, where $40.09 \%$ and $19.19 \%$ of the sample households had lost their crop production in 2011 and 2013, receptively. The plant disease, pest damage, loss, and death of animal livestock, and illness were also major sources of crop failure for the households which cause significant crop and income loss and aggravated food insecurity. These factors not only endanger the farmer's livelihood and income but also undermine the viability of agriculture sectors emergence as a solution to the problem of poverty and food insecurity of the nation.

The Ethiopian government has given great emphasis to technological changes in agricultural sectors. Improvement in technologies is a vehicle in the agricultural sector development and in reaching middle income countries beyond the more immediate goals of increasing production and satisfying food and nutritional needs. However, the use of promising agricultural technology adoptions remained very low. The result confirms that small holder farmers are not fully benefiting from modern agricultural technologies such as improved seed, fertilizer and chemical inputs and the adoption of these technologies is very low. As reported by the households lack of own cash, timely unavailability of inputs and lack of credit access are the main cause of low adoption rate of aforementioned technologies.

The study employed empirical models so as to strengthen the results obtained from the descriptive analysis. Accordingly, two stage estimation techniques were applied. Initially Antle's flexible moment based approach was applied to generate the expected output, variance of output and skewness of output and we estimated the dependent variable mean output and second and third moment of output to determine the risk increasing and decreasing factors. The finding suggests that in risky production processes, usages of input level influence both mean output and output risk. The result shows that education level, size of family labor, agricultural capital assets, manure and improved seed were significantly and positively affecting mean yield while parcel land, chemical inputs and local seed had significant and negatively affect yield. The adoption of chemical inputs and improved seed were significantly increase downside risk exposure (skewness of output) whereas, the adoption of inorganic fertilizer had negative and significant effect downside risk exposure (skewness of output).

The finding shows that how much it is important to focus not only on the mean production function, but also on the variance and skewness of production working with similar studies. Often inputs do not have significant effect on increasing the productivity, but, they may have significant effects on production risk. When making the agricultural and land management policies, it is important to consider the impact of inputs on production risk in addition to its productivity effects. Particularly the government and stakeholders should focus on improving quality and adoptability of improved seed when the improved seed is developed and distributed. Chemical inputs (pesticide and herbicide) have negative on yield and risk increasing factors, so the government and other 
responsible body should create the awareness on the efficient application of these inputs.

\section{Acknowledgements}

I am indebted to Dr. Assefa Admassie and Dr. Tadele Ferede who have constantly provided invaluable guidance, encouragement, and support throughout my study. I am grateful for institutions involved in the Ethiopian Project in Interlinking Insurance with Credit in Agriculture for allowing me to use their reach data set. These are university of California at San-Diego, university of Athens, university of Greece and FAO, EEA, Dashen Bank and Nyala Insurance Company. The financial support of Ethiopian-American Foundation and Institute of Development and Policy Research (IDPR) of Addis Ababa University is also gratefully acknowledged. In the end, I would like to express my gratitude to my family, friend and others who directly or indirectly assisted me throughout my study.

\section{References}

[1] Diagne, A., Adekambi, S.A., Simtowe, F.P. and Biaou, G. (2009) The Impact Of Agricultural Technology Adoption On Poverty: The Case of Nerica Rice Varieties in Benin. A shorter Version of the Paper Is Being Presented as Contributed Paper at the 27th Conference of the International Association of Agricultural Economists, Beijing, 16-22 August 2009.

[2] Ligon, E. and Sadoulet, E. (2007) Estimating the Effects of Aggregate Agricultural Growth on the Distribution of Expenditures. Background Note for the World Development Report 2008, the World Bank, Washington DC.

[3] MoFED (2011) Ethiopia: Sustainable Development and Poverty Reduction Program, Federal Democratic Republic of Ethiopia (FDRE), Addis Ababa, Ethiopia

[4] World Bank (2005) Ethiopia-Well-Being and Poverty in Ethiopia: The Role of Agriculture and Agency. Report No. 29468-ET. World Bank, Washington DC.

[5] IPCC (2001) Climate Change 2001: Impacts, Adaptation, and Vulnerability. Contribution of Working Group II to the Third Assessment Report of the Intergovernmental Panel on Climate Change. McCarthy, J.J., Canziani, O.F., Leary, N.A., Dokken, D.J. and White, K.S., Eds., Cambridge University Press, Cambridge, 1032 p.

[6] Parry, M.L., Arnell, N.W., McMichael, A.J., Nicholls, A.J., Martens, A.J., Kovats, R.S., Livermore, M.T.J., Rosenzweig, C., Iglesias, A. and Fischer, A. (2001) Millions at Risk: Defining Critical Climate Change Threats and Targets. Global Environmental Change, 11, 181-183. http://dx.doi.org/10.1016/S0959-3780(01)00011-5

[7] Kennedy, E., and Bouis, H.E. (1993) Linkages between Agriculture and Nutrition: Implications for Policy and Research.

[8] Von Braun, J., Teklu, T. and Webb, P. (1999) Famine in Africa: Causes, Responses, and Prevention.

[9] Longa Cochrane (2014) Agriculture Intensification in Ethiopia. Review of Recent Research: Africa Journal of Agriculture Research, 9, 2377-2390.

[10] Nin-Pratt, A. and Yu, B. (2010) Agricultural Productivity and Policy Changes in sub-Saharan Africa. USDA Economic Research Service, 1800 M St NW, Washington DC 20036.

[11] Fuglie, K.O. and Rada, N.E. (2013) Resources, Policies, and Agricultural Productivity in Sub-Saharan Africa. Economic Research Report No. 145. US Department of Agriculture, Economic Research Service.

[12] World Bank Data (2012) Agriculture and Development. http://datacatalog.worldbank.org/

[13] Berihun, B.K. (2014) Adoption and Impact of Agricultural Technologies on Farm Income: Evidence from Southern Tigray, Northern Ethiopia. International Journal of Food and Agricultural Economics, 2, 91-106.

[14] Asfaw, S. and Shiferaw, B. (2010) Agricultural Technology Adoption and Rural Poverty: Application of an Endogenous Switching Regression for Selected East African Countries. African Association of Agricultural Economists (AAAE), Nairobi.

[15] Feleke, S. and Zegeye, T. (2006) Adoption of Improved Maize Variety in Southern Ethiopia: Factors and Strategy Options. Food Policy, 31, 442-457. http://dx.doi.org/10.1016/j.foodpol.2005.12.003

[16] Antle, J. (1983) Testing the Stochastic Structure of Production: A Flexible Moment Based Approach. Journal of Business and Economic Statistics, 1, 92-201.

[17] Antle, J. (1987) Econometric Estimation of Producers’ Risk Attitudes. American Journal of Agricultural Economics, 69, 509-522. http://dx.doi.org/10.2307/1241687

[18] Kassie, M., Zikhali, P., Manjur, K. and Edwards, S. (2009) Adoption of Sustainable Agricultural Practices: Evidence from a Semi-Arid Region of Ethiopia. Natural Resources Forum, 33, 189-198. 
http://dx.doi.org/10.1111/j.1477-8947.2009.01224.x

[19] Roll, K.H., Guttormsen, A.G. and Asche, F. (2006) Modelling Production Risk in Small Scale Subsistence Agriculture. Contributed Paper Prepared for Presentation at the International Association of Agricultural Economists Conference, Gold Coast, 12-18 August 2006.

[20] Koundouri, P., Laukkanen, M., Myyrä, S. and Nauges, C. (2009) The Effects of EU Agricultural Policy Changes on Farmers’ Risk Attitudes. European Review of Agricultural Economics, 36, 53-77. http://dx.doi.org/10.1093/erae/jbp003

[21] Ogada, M.J., Mwabu, G. and Muchai, D. (2014) Farm Technology Adoption in Kenya: A Simultaneous Estimation of Inorganic Fertilizer and Improved Maize Variety Adoption Decisions. ILRI, Nairobi, Kenya.

[22] Ahmed, S., Gommes, R., McIntosh, C. and Sarris, A. (2011) Interlinking Insurance with Credit to Enhance Smallholder Agricultural Productivity: A Pilot Application to Ethiopia. FERDI Policy Brief B23.

[23] McIntosh, C., Sarris, A. and Papadopoulos, F. (2013) Productivity, Credit, Risk, and the Demand for Weather Index Insurance in Smallholder Agriculture in Ethiopia. Agricultural Economics, 44, 399-417. http://dx.doi.org/10.1111/agec.12024

[24] Meinzen-Dick, R., Knox, A., Place, F. and Swallow, B. (2004) Innovation in Natural Resources Management: The Role of Property Rights and Collective Action in Developing Countries.

[25] Binswanger, H.P. (1980) Attitudes toward Risk: Experimental Measurement in Rural India. American Journal of Agricultural Economics, 62, 395-407. http://dx.doi.org/10.2307/1240194

[26] Mundlak, Y. (1978) On the Pooling of Time Series and Cross-Section Data. Econometrica, 46, $69-85$. http://dx.doi.org/10.2307/1913646

[27] Bisanda, S. and Mwangi, W. (1996) Farmers’ Adoption of Improved Maize Varieties in Mbeya Region of the Southern Highlands of Tanzania.

[28] Feder, G., Just, R.E. and Zilberman, D. (1985) Adoption of Agricultural Innovations in Developing Countries: A Survey. Economic Development and Cultural Change, 33, 255-298. http://dx.doi.org/10.1086/451461

[29] Martey, E., Wiredu, A.N., Etwire, P.M., Fosu, M., Buah, S.S.J., Bidzakin, J., Ahiabor, B.D.K. and Kusi, F. (2013) Fertilizer Adoption and Use Intensity among Smallholder Farmers in Northern Ghana: A Case Study of the AGRA Soil Health Project. Sustainable Agriculture Research, 3, 24-36. http://dx.doi.org/10.5539/sar.v3n1p24

[30] Just, R.E. and Pope, R.D. (1979) Stochastic Specification of Production Functions and Economics Implications. Journal of Econometrics, 7, 67-86. http://dx.doi.org/10.1016/0304-4076(78)90006-4

[31] Nishikawa, Y. (2012) Good Quality Seeds and Linking Formal Seed System with Farmers’ Own Perspectives and Initiatives: A Japanese Experience. http://www.eiar.gov.et

[32] Oerke, E.C. and Dehne, H.W. (2004) Safeguarding Production-Losses in Major Crops and the Role of Crop Protection. Crop Protection, 23, 275-285. 